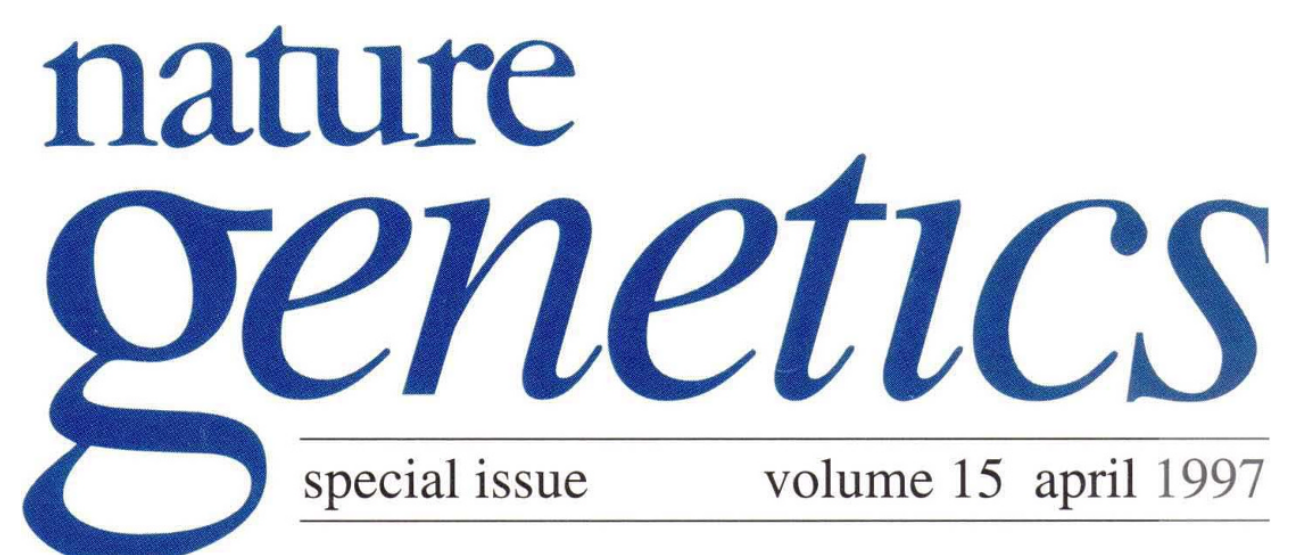

\title{
Cancer research breaks out
}

For the past 25 years, Felix Mitelman and colleagues at the University Hospital in Lund, Sweden, have been compiling an extraordinary database of chromosomal aberrations associated with human cancer. By the end of last year, the database consisted of some 27,000 neoplasms with different chromosomal aberrations. The results of this mammoth effort have been published every few years in the book Catalog of Chromosome Aberrations in Cancer (published by Wiley-Liss) which last appeared in 1994. This two-volume tome lists every chromosome aberration on a case-by-case, chromosome-by-chromosome basis.

Recently, however, Mitelman, who is one of the editors of the journal Genes, Chromosomes and Cancer, and his colleagues, Fredrik Mertens and Bertil Johansson, have been analyzing their dataset in a different way - by examining the frequency with which specific genes and chromosomal regions are disrupted in human tumours. The results of this daunting enterprise - one of the peer reviewers of the article in this issue noted that "only Mitelman would be crazy enough" to attempt such a task - are presented in this special supplement of Nature Genetics (the paper should be cited in the usual way, that is, volume 15, pages 417-474). Mitelman and coworkers present a comprehensive synthesis of known cancer-related breakpoints mapped to the human genome, and document the recurrence rate for every chromosomal aberration recorded in the literature up until the latter half of last year.

The power of this unique resource is discussed by the Director of the National Cancer Institute (NCI), Richard Klausner, and two senior colleagues, Robert Strausberg and Carol Dahl, in the accompanying News \& Views. The NCI, which has generously helped to defray the costs of this special issue, is understandably excited about its plans for a new initiative known as the Cancer Genome Anatomy Project, an ambitious programme to put in place infrastructure that will allow for the determination of the precise genetic changes associated with cancer at many levels, including structural and transcriptional changes. Clearly, the work of Mitelman and colleagues will provide a crucial underpinning to this worthwhile goal, especially if plans to produce a comprehensive database for genetic changes in cancer take off.

The one previous Nature Genetics supplement in 1994 featured the human genetic linkage map produced by the Généthon group in Paris, and has been among the most highly cited research papers ever since. We hope that the sterling efforts of Mitelman's team will prove of equal value to the cancer research community and beyond. 